\title{
The health effects of work-family conflict in men and women Japanese civil servants: a longitudinal study
}

\author{
Uta KOURA $^{1 *}$, Michikazu SEKINE ${ }^{1}$, Masaaki YAMADA ${ }^{1}$ and Takashi TATSUSE ${ }^{1}$ \\ ${ }^{1}$ Department of Epidemiology and Health Policy, University of Toyama Graduate School of Medicine and \\ Pharmaceutical Sciences, Japan
}

Received October 31, 2019 and accepted April 17, 2020

Published online in J-STAGE May 21, 2020

\begin{abstract}
High level of work-family conflict (WFC) is an important risk factor for stress-related health outcomes. However, many studies are cross-sectional studies. In this study, we aimed to clarify how changes in WFC levels over a period $5 \mathrm{yr}$ can affect workers' mental and physical health, and to clarify whether there are gender differences of them. This study examined 1,808 civil servants $(1,258$ men and 550 women) aged $20-65$ yr working in a local government in the west coast of Japan from 2003 to 2008. Logistic regression analyses were used to examine whether the change in WFC contributes to workers' health problems and whether there are gender differences. This study revealed association sustained high WFC and deterioration of WFC conflict with poor mental health and poor job satisfaction for both men and women. In men high WFC conflict and deterioration was associated with poor mental health $(\mathrm{OR}=2.74)$. On the other hand, women had strong relationship between WFC changes and poor physical health $(\mathrm{OR}=2.64)$. WFC was an important factor as a social determinant of health of Japanese civil servants, and the change in WFC affects subsequent health problems with different trends in men and women.
\end{abstract}

Key words: Work-family conflict, Mental health, Physical health, Job satisfaction, Self-rated health

\section{Introduction}

In recent years, the relationship between work and family-life has been becoming more complex due to changes in the social situation, workplace and home environment. According to the Japan's Labor Force Survey of 2014, there were approximately 11.1 million double-income and 6.8 million single-income households in Japan ${ }^{1,2)}$. Double-

\footnotetext{
*To whom correspondence should be addressed.

E-mail: utakoura@gmail.com

(Supplementary material: refer to PMC https://www.ncbi.nlm.nih.gov/ pmc/journals/2597/)

(C)2020 National Institute of Occupational Safety and Health
}

income households have continued to increase since 2005 and now include the majority of Japanese couples ${ }^{3)}$. These social backgrounds have advantages of women's social advancement and gender equality, but many workers feel conflicts from multiple roles and responsibilities in the family-life, workplace, and community ${ }^{4}$. Work-family conflict (WFC) has been defined as "a form of interrole conflict in which the role pressures from the work and family domains are mutually incompatible in some respect"5).

Research has suggested that a high level of WFC may cause stress-related health outcomes such as psychological strain, anxiety and depression, somatic complaints, hypertension, and alcohol abuse ${ }^{6-10)}$. Therefore, a high level of WFC is an important risk factor for physical and mental 
health problems. Although there have been many studies on WFC and health problems, there are only a few studies on the long-term impact of WFC on health ${ }^{9}$.

Evidence about gender differences in WFC is controversial. Several meta-analysis have found no gender differences in $\mathrm{WFC}^{11-13)}$, but a cross-sectional study based on a representative sample of the Swiss employed population aged 20 to 64 (1,591 men and 1,661 women) has shown that gender acts as a moderator of WFC and that women experience higher WFC than men in the same occupational position; the study indicated that the lack of gender difference in WFC was artificial ${ }^{14)}$. Our previous study of Japanese civil servants showed that women had higher WFC than men ${ }^{4)}$. In another Japanese study the gender difference was also evident and the p-sex interaction was 0.02 . The health effects of work-family conflict were more evident only in women with low income ${ }^{15)}$. The factors contributing to such gender differences are not yet fully understood.

In this study, we aimed to clarify how sustainable high WFC and deterioration of WFC affect workers' mental and physical health, and to determine gender differences of them. The main reason for studying WFC was that clarifying what kind of change of WFC influences health problem not only furthers our understanding of the worklife balance, but also has the potential to contribute to recommendations for effective improvements for workers with mental or physical health problems.

\section{Subjects and Methods}

\section{Participants}

The study population comprised the participants in the Japanese civil servants study (the JACS study) phase 2 and 3, which was conducted in collaboration with the Whitehall 2 study of British civil servants and the Helsinki Health Study (HHS) of civil servants of the city of Helsinki ${ }^{4,16-18)}$. Phase 2 was conducted in January and February 2003 and phase 3 was conducted in January and February 2008. These study included all civil servants aged 20-65 yr working in local government in the west coast of Japan at the time of the survey. The survey was administered via a postal questionnaire returned to the researchers in sealed envelopes. The questionnaire items were selected from the Whitehall 2 Study and translated into Japanese.

A total of 4,272 participants (response rate: $79.2 \%$ ) responded in phase 2 and 4,492 participants (response rate: $91.0 \%$ ) responded in phase 3 . Three thousand three hundred eighty nine people could be followed from phase 2 to phase 3. Any questionnaire in which a respondent failed to answer one or more questions related to the variables used in this study (WFC, age, marital status, children, job type, psychosocial work characteristics, working hours, shift work, mental health, physical health, self-rated health, and job satisfactions) was excluded from the analysis, resulting in data from 1,808 participants $(1,258$ men and 550 women $)$ being included in the final analysis. Excluded groups tended to have lower mental health, self-rated health, and job satisfaction, and higher age, but there were no significant differences between excluded and recruited groups.

The Japanese civil servants study was associated with the annual health checkups regulated by Japan's Industrial Safety and Health Law. An ad hoc committee of the civil service, comprising an ordinary member of the Safety and Health Committee as well as labor and personnel representatives, approved the contents and ethical aspects of the study. Informed consent was obtained from all participants, and all participants voluntarily. The Institutional Review Board of the University of Toyama approved the study.

\section{Measures}

Work-family conflict

Eight items related to work-to-family and family-towork conflicts were selected from the US National Study of Midlife Development ${ }^{19)}$ and included. Each shows the strength of the interference and responsibilities to the home from work and vice versa. Previous studies have proposed that work-to-family and family-to-work conflict scores can be summed ${ }^{20)}$, so the answers to these eight items were summed to give a total WFC score in each phase. These items scored from one to three points with higher scores indicating more conflicts. In our study the range of score was $8-22$ in phase 2 and $8-24$ in phase 3 . Dichotomies were formed to divide the participants into two groups for analysis: high WFC and low WFC. Cut off point in phase 2 was 11 and 12 in phase 3. Participants were divided into high-high, high-low, low high and lowlow group from the results of WFC in phase 2 and 3. In this population, Cronbach's $\alpha$ of W-F conflict was 0.82 in phase 2 and 0.73 on phase 3 , cronbach's $\alpha$ a of F-W conflict was 0.72 in phase 2 and 0.83 in phase 3 , and cronbach's $\alpha$ of total WFC was 0.81 in phase 2 and 0.82 in phase 3 , indicating high internal consistency. We also used uncombined WFC scores to examine the effects of workto-family and family-to-work conflicts. 
Physical and mental functioning

The physical and mental functioning of the participants was assessed using the Japanese version of the 36-Item Short Form Health Survey (SF-36), which has been validated and widely used in Japan ${ }^{21)}$. The original questionnaire is used worldwide ${ }^{22)}$. The Japanese version consists of 36 items related to eight subscales, with higher scores representing better health. Physical and mental component summary scores (PCS and MCS, respectively) were obtained by multiplying each z-score (standardized for each subscale by using data from the general US population) by its physical or mental factor score coefficient and adding the eight products. Cronbach's $\alpha$ for the Japanese version ranged from 0.71 to 0.91 and the test-retest reliability from 0.78 to 0.86 , indicating good validity and reliability $^{21)}$. The range of PCS score was 8.9-68.2 in phase 2 and $10.0-71.2$ in phase 3. The range of MCS score was 5.6-63.4 in phase 2 and 6.8-63.5 in phase 3. The lowest quintile was used as a cutoff point. The cut off point of PCS was 44 in phase 2 and 44 in phase 3 . MCS was 38 in phase 2 and 37 in phase 3 .

\section{Self-rated health}

General self-rated health, a simple measure of subjective health status, has been predicted morbidity and mortal${ }^{i t y}{ }^{23)}$. In this study, self-rated health was questioned 'How would you rate your general state of health?' Respondents answered on a 5-point scale and the participants divided into poor ('poor' and 'very poor') and good ('neither good nor poor', ' good' and 'very good”).

\section{Job satisfaction}

Many studies have suggested relationships between job satisfaction and mental health ${ }^{24,25)}$. To assess job satisfaction, the participants were asked whether they were satisfied with their job overall, and were then divided into two groups for the analysis, "satisfied" or "dissatisfied". A previous report showed that the reliability of single-item measure of job satisfaction is $0.68^{26)}$.

\section{Covariates}

Age, changing domestic roles, and changing work characteristics were included in the analysis as they could be expected to confound relationships between WFC and health. The variables of domestic role included changes from phase 2 to 3 of marriage and children under $15 \mathrm{yr}$ of age living together. Changes in marital status were classified into four categories based on only the married or unmarried in each phase, therefore both "yes-no" and "no- no" include single, divorce, and widower.

The variables of work characteristics included job category and changes from phase 2 to 3 of psychosocial work characteristics, working hours $(9 \mathrm{~h}$ or more was taken as long working hours), and shift work. The participants' occupations were classified into four categories in alignment with the major occupation groups of the Japanese census: clerical workers, administrative workers, professional and technical workers (technicians, teachers, and healthcare professionals), and others. This classification has been used in previous studies ${ }^{25}$ 27). Psychosocial work characteristics were assessed using the job demand-controlsupport model ${ }^{28)}$. This comprises 25 items covering job control, job demand, and social support at work. In this population, the Cronbach's $\alpha$ s were 0.79 for job control, 0.69 for demand, and 0.83 for social support, indicating high internal consistency. In the analysis, the scales were grouped into 2-quantiles in each phase and the participants were divided into high-high, high-low, low-high and lowlow group from the results of demand, control, and support in phase 2 and 3.

\section{Statistical analysis}

To compare background variables between categories of gender and changes of WFC, $\chi^{2}$ was performed. Logistic regression analyses were used to examine the associations between changes of WFC and the health indicators. Model 1 shows age-adjusted individual effects of WFC. Model 2 controlled for age and domestic role factors (changes of marriage and children under $15 \mathrm{yr}$ of age living together). Model 3 controlled for age, domestic role factors, and work characteristics (job category and changes of psychosocial work characteristics, working hours, and shift work). Model 4 controlled for age, domestic role factors, work characteristics, and corresponding health variable at baseline (i.e. low mental health, poor job satisfaction, low physical health, and poor self-rated health). Odds ratios (ORs) were calculated with $95 \%$ confidence intervals. The Hosmer-Lemeshow test was used to validate the multivariate models. The statistical analyses were performed using IBM SPSS software (20.0.j). A two-tailed $p$ value less than 0.05 was considered significant.

\section{Results}

Table 1 shows the participants' characteristics by gender. Gender differences were revealed in almost all variables except for changes for support in job characteristics.

Table 2 shows that WFC changes were significantly as- 
Table 1. Characteristics of the participants by gender

\begin{tabular}{|c|c|c|c|}
\hline Characteristics & $\begin{array}{c}\text { Men } \\
(\mathrm{N}=1,258) \\
\%\end{array}$ & $\begin{array}{c}\text { Women } \\
(\mathrm{N}=550) \\
\%\end{array}$ & $\begin{array}{c}\chi^{2} \text { test } \\
p \text {-value }\end{array}$ \\
\hline \multicolumn{4}{|l|}{ WFC } \\
\hline high-high & 23.0 & 39.7 & 0.00 \\
\hline high-low & 15.3 & 20.0 & \\
\hline low-high & 15.7 & 12.8 & \\
\hline low-low & 46.1 & 27.5 & \\
\hline \multicolumn{4}{|l|}{ Age } \\
\hline $20-24$ & 0.6 & 7.7 & 0.00 \\
\hline $25-34$ & 28.4 & 32.8 & \\
\hline $35-44$ & 34.6 & 33.9 & \\
\hline $45-54$ & 35.0 & 24.9 & \\
\hline $55-64$ & 1.4 & 0.6 & \\
\hline \multicolumn{4}{|l|}{ Marital status } \\
\hline yes-yes & 78.7 & 66.3 & 0.00 \\
\hline yes-no & 2.4 & 2.8 & \\
\hline no-yes & 8.0 & 10.7 & \\
\hline no-no & 10.9 & 20.3 & \\
\hline \multicolumn{4}{|l|}{ Young children } \\
\hline yes-yes & 41.5 & 35.4 & 0.01 \\
\hline yes-no & 13.2 & 13.2 & \\
\hline no-yes & 17.9 & 15.6 & \\
\hline no-no & 27.3 & 35.8 & \\
\hline \multicolumn{4}{|l|}{ Job type } \\
\hline Cclerical & 33.3 & 29.2 & 0.00 \\
\hline Administrative & 3.9 & 0.2 & \\
\hline Professional & 54.7 & 68.7 & \\
\hline Others & 8.1 & 1.9 & \\
\hline \multicolumn{4}{|l|}{ Control } \\
\hline high-high & 36.2 & 26.0 & 0.00 \\
\hline high-low & 14.9 & 14.3 & \\
\hline low-high & 18.0 & 20.7 & \\
\hline low-low & 30.9 & 39.0 & \\
\hline \multicolumn{4}{|l|}{ Demand } \\
\hline high-high & 17.5 & 29.4 & 0.00 \\
\hline high-low & 17.5 & 25.6 & \\
\hline low-high & 15.1 & 11.3 & \\
\hline low-low & 50.0 & 33.7 & \\
\hline \multicolumn{4}{|l|}{ Support } \\
\hline high-high & 31.1 & 27.7 & 0.29 \\
\hline high-low & 19.5 & 23.2 & \\
\hline low-high & 18.1 & 17.3 & \\
\hline low-low & 31.3 & 31.8 & \\
\hline \multicolumn{4}{|l|}{ Work hours } \\
\hline long-long & 17.6 & 22.4 & 0.04 \\
\hline long-short & 14.3 & 16.8 & \\
\hline short-long & 16.2 & 15.6 & \\
\hline short-short & 51.9 & 45.2 & \\
\hline
\end{tabular}

\begin{tabular}{lccc}
\hline Characteristics & $\begin{array}{c}\text { Men } \\
(\mathrm{N}=1,258) \\
\%\end{array}$ & $\begin{array}{c}\text { Women } \\
(\mathrm{N}=550) \\
\%\end{array}$ & $\begin{array}{c}\chi^{2} \text { test } \\
p \text {-value }\end{array}$ \\
\hline $\begin{array}{l}\text { Shift work } \\
\quad \text { yes-yes }\end{array}$ & 3.7 & 31.3 & 0.00 \\
$\quad$ yes-no & 3.9 & 12.6 & \\
no-yes & 3.9 & 3.6 & \\
$\quad$ no-no & 88.5 & 52.5 & \\
Mental health (base line) & & & \\
$\quad$ high & 84.5 & 74.2 & 0.00 \\
$\quad$ low & 15.5 & 25.8 & \\
Job satisfaction (base line) & & & \\
$\quad$ yes & 67.2 & 61.6 & 0.04 \\
$\quad$ no & 32.8 & 38.4 & \\
Physical health (base line) & & & \\
$\quad$ high & 84.2 & 78.3 & 0.01 \\
$\quad$ low & 15.8 & 21.7 & \\
Self-rated health (base line) & & & \\
$\quad$ good & 64.8 & 64.0 & 0.77 \\
$\quad$ poor & 35.2 & 36.0 & \\
\hline
\end{tabular}

WFC: work-family conflict.

sociated with health outcomes, age and changes of marital status, children, job characteristics, and work hours. Sustained high WFC category (high-high) and deterioration of WFC category (low-high) was younger than other categories. Sustained high WFC was more common among married, having children, professional workers, high demand, low support job, long working hours, and shift work.

Table 3 shows the associations between changes of WFC and the health indicators (low mental health, poor job satisfaction, low physical health, and poor self-rated health) for men. In comparison to low-low WFC, the ageadjusted OR of high-high WFC was 4.10 for low mental health, 3.21 for poor job satisfaction, 2.25 for low physical health, and 2.90 for poor self-rated health (Model 1). In comparison to low-low WFC, the age-adjusted OR of lowhigh WFC was 2.44 for low mental health, 1.92 for poor job satisfaction, and 2.00 for poor self-rated health (Model 1). Model 2 (adjusting for age and domestic role factors) and Model 3 (adjusting for age, domestic role factors, and work characteristics) did not alter the results. Final model, additionally controlled for the corresponding health variable at baseline, shows high-high WFC significantly associated with low mental health (OR: 2.74), poor job satisfaction (OR: 2.50), low physical health (OR: 1.53), and poor self-rated health (OR: 2.00).

Table 4 shows the associations between changes of 
Table 2. Characteristics of the participants by WFC changes

\begin{tabular}{|c|c|c|c|c|c|c|}
\hline \multirow{2}{*}{ Characteristics } & & \multicolumn{4}{|c|}{ WFC changes } & \multirow{2}{*}{$\chi^{2}$} \\
\hline & & high-high & high-low & low-high & low-low & \\
\hline $\mathrm{N}$ & & 506 & 264 & 323 & 715 & \\
\hline \multirow[t]{2}{*}{ Age 2003} & & $39.3 \pm 7.6$ & $41.7 \pm 8.1$ & $37.5 \pm 8.9$ & $40.5 \pm 9.3$ & \\
\hline & $\mathrm{N}$ & $\%$ & $\%$ & $\%$ & $\%$ & \\
\hline \multicolumn{7}{|l|}{ Sex } \\
\hline Men & 1,258 & 23.1 & 16.0 & 15.5 & 45.4 & 0.00 \\
\hline Women & 550 & 40.2 & 19.6 & 12.4 & 27.8 & \\
\hline \multicolumn{7}{|l|}{ Marital status } \\
\hline yes-yes & 1,360 & 32.3 & 18.4 & 13.1 & 36.2 & 0.00 \\
\hline yes-no & 47 & 23.4 & 29.8 & 17.0 & 29.8 & \\
\hline no-yes & 158 & 14.6 & 8.2 & 32.3 & 44.9 & \\
\hline no-no & 233 & 15.0 & 13.7 & 10.3 & 60.9 & \\
\hline \multicolumn{7}{|l|}{ Young children } \\
\hline yes-yes & 708 & 35.6 & 18.9 & 12.3 & 33.2 & 0.00 \\
\hline yes-no & 253 & 26.9 & 17.8 & 13.0 & 42.3 & \\
\hline no-yes & 312 & 26.3 & 14.4 & 21.5 & 37.8 & \\
\hline no-no & 535 & 20.6 & 15.9 & 14.2 & 49.3 & \\
\hline \multicolumn{7}{|l|}{ Job type } \\
\hline Clerical & 564 & 26.1 & 16.1 & 14.4 & 43.4 & 0.02 \\
\hline Administrative & 59 & 16.9 & 23.7 & 13.6 & 45.8 & \\
\hline Professional & 1,064 & 31.1 & 17.4 & 14.7 & 36.8 & \\
\hline Others & 121 & 19.8 & 15.7 & 14.9 & 49.6 & \\
\hline \multicolumn{7}{|l|}{ Control } \\
\hline high-high & 580 & 24.5 & 18.4 & 13.1 & 44.0 & 0.07 \\
\hline high-low & 262 & 29.0 & 16.0 & 16.8 & 38.2 & \\
\hline low-high & 333 & 27.6 & 15.9 & 13.5 & 42.9 & \\
\hline low-low & 572 & 32.2 & 16.1 & 15.9 & 35.8 & \\
\hline \multicolumn{7}{|l|}{ Demand } \\
\hline high-high & 369 & 48.2 & 15.2 & 16.8 & 19.8 & 0.00 \\
\hline high-low & 354 & 27.7 & 28.2 & 9.3 & 34.7 & \\
\hline low-high & 253 & 30.4 & 13.4 & 24.5 & 31.6 & \\
\hline low-low & 811 & 18.7 & 14.3 & 12.7 & 54.3 & \\
\hline \multicolumn{7}{|l|}{ Support } \\
\hline high-high & 529 & 22.7 & 16.1 & 14.4 & 46.9 & 0.00 \\
\hline high-low & 364 & 34.1 & 16.2 & 16.5 & 33.2 & \\
\hline low-high & 320 & 22.2 & 21.2 & 14.7 & 41.9 & \\
\hline low-low & 567 & 33.2 & 16.4 & 13.8 & 36.7 & \\
\hline \multicolumn{7}{|l|}{ Work hours } \\
\hline long-long & 338 & 45.0 & 18.0 & 15.7 & 21.3 & 0.00 \\
\hline long-short & 274 & 28.1 & 28.5 & 13.1 & 30.3 & \\
\hline short-long & 289 & 31.1 & 9.0 & 20.1 & 39.8 & \\
\hline short-short & 898 & 21.2 & 15.9 & 12.7 & 50.2 & \\
\hline \multicolumn{7}{|l|}{ Shift work } \\
\hline yes-yes & 228 & 47.8 & 18.0 & 14.0 & 20.2 & 0.00 \\
\hline yes-no & 122 & 27.9 & 24.6 & 13.9 & 33.6 & \\
\hline no-yes & 75 & 32.0 & 17.3 & 13.3 & 37.3 & \\
\hline no-no & 1,382 & 25.0 & 16.2 & 14.8 & 44.1 & \\
\hline Low mental health 2008 & 333 & 47.4 & 11.4 & 19.5 & 21.6 & 0.00 \\
\hline Poor job satisfaction 2008 & 526 & 42.8 & 12.9 & 17.3 & 27.0 & 0.00 \\
\hline Low physical health 2008 & 383 & 41.0 & 17.2 & 12.8 & 29.0 & 0.00 \\
\hline Poor self-rated health 2008 & 594 & 40.7 & 13.8 & 16.8 & 28.6 & 0.00 \\
\hline
\end{tabular}

WFC: work-family conflict. 
Table 3. Relation between changes of WFC and the health indicators for men $(N=1,258)$

\begin{tabular}{|c|c|c|c|c|c|}
\hline & $\begin{array}{l}\text { Prevalence of each } \\
\text { outcomes }\end{array}$ & $\begin{array}{c}\text { Model } 1 \\
\text { (age-adjusted) }\end{array}$ & $\begin{array}{c}\text { Model } 2 \\
(1+\text { Domestic role })\end{array}$ & $\begin{array}{l}\text { Model } 3 \\
(2+\text { work })\end{array}$ & $\begin{array}{c}\text { Model } 4 \\
\text { (3+baseline) }\end{array}$ \\
\hline & $\%$ & Odds ratio $(95 \% \mathrm{CI})$ & Odds ratio $(95 \% \mathrm{CI})$ & Odds ratio $(95 \% \mathrm{CI})$ & Odds ratio $(95 \% \mathrm{CI})$ \\
\hline \multicolumn{6}{|c|}{ Low mental health } \\
\hline \multicolumn{6}{|l|}{ WFC } \\
\hline high-high & 21.8 & $4.10(2.82-5.96)$ & $4.73(3.21-6.97)$ & $4.02(2.61-6.20)$ & $2.74(1.73-4.33)$ \\
\hline high-low & 6.6 & $1.20(0.71-2.03)$ & $1.33(0.78-2.26)$ & $1.30(0.74-2.28)$ & $0.88(0.48-1.61)$ \\
\hline low-high & 17.8 & $2.44(1.57-3.80)$ & $2.66(1.69-4.16)$ & $2.29(1.42-3.69)$ & $2.09(1.27-3.43)$ \\
\hline low-low & 8.1 & 1 & 1 & 1 & 1 \\
\hline \multicolumn{6}{|c|}{ Poor job satisfaction } \\
\hline \multicolumn{6}{|l|}{ WFC } \\
\hline high-high & 32.6 & $3.21(2.35-4.40)$ & $3.63(2.63-5.02)$ & $2.75(1.91-3.96)$ & $2.50(1.73-3.43)$ \\
\hline high-low & 18.9 & $1.37(0.93-2.01)$ & $1.50(1.02-2.22)$ & $1.36(0.89-2.08)$ & $1.28(0.83-1.96)$ \\
\hline low-high & 30.6 & $1.92(1.33-2.79)$ & $2.09(1.43-3.03)$ & $1.81(1.21-2.70)$ & $1.81(1.21-2.70)$ \\
\hline low-low & 15.2 & 1 & 1 & 1 & 1 \\
\hline \multicolumn{6}{|c|}{ Low physical health } \\
\hline \multicolumn{6}{|l|}{ WFC } \\
\hline high-high & 20.1 & $2.25(1.59-3.17)$ & $2.38(1.68-3.37)$ & $1.91(1.29-2.83)$ & $1.53(1.01-2.32)$ \\
\hline high-low & 9.8 & $0.91(0.58-1.43)$ & $0.93(0.59-1.48)$ & $0.85(0.52-1.38)$ & $0.72(0.43-1.21)$ \\
\hline low-high & 9.6 & $0.88(0.55-1.41)$ & $0.86(0.53-1.39)$ & $0.77(0.47-1.27)$ & $0.60(0.35-1.03)$ \\
\hline low-low & 12.6 & 1 & 1 & 1 & 1 \\
\hline \multicolumn{6}{|c|}{ Poor self-rated health } \\
\hline \multicolumn{6}{|l|}{ WFC } \\
\hline high-high & 24.8 & $2.90(2.15-3.92)$ & $3.04(2.24-4.14)$ & $2.71(1.92-3.82)$ & $2.00(1.39-2.89)$ \\
\hline high-low & 16.3 & $1.15(0.80-1.66)$ & $1.19(0.83-1.72)$ & $1.19(0.80-1.76)$ & $1.05(0.70-1.59)$ \\
\hline low-high & 27.9 & $2.00(1.42-2.84)$ & $2.03(1.43-2.88)$ & $1.89(1.30-2.74)$ & $1.97(1.33-2.92)$ \\
\hline low-low & 18.1 & 1 & 1 & 1 & 1 \\
\hline
\end{tabular}

WFC: work-family conflict.

Model 1: adjusted for age.

Model 2: adjusted for age and domestic role factors. Domestic role factors were changes in marital status and changes in children under 15 yr of age from phase 2 to phase 3 .

Model 3: adjusted for age, domestic role factors, and work characteristics. Work characteristics were job category in phase 2 and changes of psychosocial work characteristics, long working hours, and shift work from phase 2 to phase 3.

Model 4: adjusted for age, domestic role factors, work characteristics, and corresponding health variable at baseline (i.e. low mental health, poor job satisfaction, low physical health, and poor self-rated health).

WFC and the health indicators (low mental health, poor job satisfaction, low physical health, and poor self-rated health) for women. In comparison to low-low WFC, the age-adjusted OR of high-high WFC was 3.52 for low mental health, 3.12 for poor job satisfaction, 2.79 for low physical health, and 3.85 for poor self-rated health (Model 1). In comparison to low-low WFC, the age-adjusted OR of low-high WFC was 4.13 for low mental health, 2.81 for poor job satisfaction, 2.94 for low physical health, and 2.63 for poor self-rated health (Model 1). Further the age-adjusted OR of high-low WFC was 2.84 for low physical health. Model 2 (adjusting for age and domestic role factors) and Model 3 (adjusting for age, domestic role factors, and work characteristics) did not alter the results.
Final model, additionally controlled for the corresponding health variable at baseline, shows high-high WFC significantly associated with low mental health (OR: 3.07$)$, poor job satisfaction (OR: 2.45), and poor self-rated health (OR: 2.39), low-high WFC significantly associated with low mental health (OR: 4.76), poor job satisfaction (OR: 2.89), low physical health (OR: 2.64), and poor self-rated health (OR: 2.38).

Supplemental Tables 1 and 2 shows relation between changes of work to family conflict and family to work conflict and the health indicators. In final model shows low-high family-to-work conflict significantly associated with low physical health in only women (OR: 2.06). 
Table 4. Relation between changes of WFC and the health indicators for women $(\mathrm{N}=550)$

\begin{tabular}{|c|c|c|c|c|c|}
\hline & $\begin{array}{c}\text { Prevalence of each } \\
\text { outcomes }\end{array}$ & $\begin{array}{c}\text { Model } 1 \\
\text { (age-adjusted) }\end{array}$ & $\begin{array}{c}\text { Model } 2 \\
(1+\text { Domestic role })\end{array}$ & Model 3 (2+work) & Model 4 ( $3+$ baseline) \\
\hline & $\%$ & Odds ratio $(95 \% \mathrm{CI})$ & Odds ratio $(95 \% \mathrm{CI})$ & Odds ratio $(95 \% \mathrm{CI})$ & Odds ratio $(95 \% \mathrm{CI})$ \\
\hline \multicolumn{6}{|l|}{ Low mental health } \\
\hline \multicolumn{6}{|l|}{ WFC } \\
\hline high-high & 20.4 & $3.52(1.97-6.29)$ & $4.59(2.41-8.73)$ & $3.70(1.86-7.35)$ & $3.07(1.47-6.39)$ \\
\hline high-low & 10.5 & $1.36(0.65-2.84)$ & $1.58(0.74-3.34)$ & $1.32(0.60-2.91)$ & $1.15(0.50-2.67)$ \\
\hline low-high & 32.1 & $4.13(2.02-8.42)$ & $4.55(2.20-9.42)$ & $4.16(1.95-8.87)$ & $4.76(2.17-10.47)$ \\
\hline low-low & 10.2 & 1 & 1 & 1 & 1 \\
\hline \multicolumn{6}{|c|}{ Poor job satisfaction } \\
\hline \multicolumn{6}{|l|}{ WFC } \\
\hline high-high & 30.5 & $3.12(1.95-5.02)$ & $3.60(2.13-6.10)$ & $2.83(1.59-5.07)$ & $2.45(1.35-4.44)$ \\
\hline high-low & 10.5 & $0.82(0.43-1.54)$ & $0.88(0.46-1.68)$ & $0.68(0.34-1.37)$ & $0.61(0.30-1.23)$ \\
\hline low-high & 43.2 & $2.81(1.52-5.21)$ & $2.97(1.59-5.55)$ & $2.70(1.38-5.27)$ & $2.89(1.46-5.72)$ \\
\hline low-low & 17.2 & 1 & 1 & & 1 \\
\hline \multicolumn{6}{|c|}{ Low physical health } \\
\hline \multicolumn{6}{|l|}{ WFC } \\
\hline high-high & 25.2 & $2.79(1.65-4.72)$ & $2.81(1.60-4.96)$ & $2.46(1.32-4.59)$ & $1.88(0.97-3.65)$ \\
\hline high-low & 28.6 & $2.84(1.56-5.17)$ & $2.83(1.53-5.22)$ & $2.99(1.55-5.75)$ & $2.46(1.23-4.91)$ \\
\hline low-high & 30.2 & $2.94(1.50-5.76)$ & $2.75(1.39-5.43)$ & $2.75(1.34-5.67)$ & $2.64(1.23-5.63)$ \\
\hline low-low & 9.3 & 1 & 1 & 1 & 1 \\
\hline \multicolumn{6}{|c|}{ Poor self-rated health } \\
\hline \multicolumn{6}{|l|}{ WFC } \\
\hline high-high & 30.8 & $3.85(2.35-6.32)$ & $4.20(2.44-7.22)$ & $3.20(1.79-5.73)$ & $2.39(1.30-4.41)$ \\
\hline high-low & 14.7 & $1.32(0.71-2.44)$ & $1.37(0.73-2.57)$ & $1.19(0.61-2.32)$ & $0.98(0.49-1.97)$ \\
\hline low-high & 27.5 & $2.63(1.37-5.06)$ & $2.64(1.36-5.10)$ & $2.31(1.15-4.65)$ & $2.38(1.15-4.94)$ \\
\hline low-low & 10.8 & 1 & 1 & 1 & 1 \\
\hline
\end{tabular}

WFC: work-family conflict.

Model 1: adjusted for age.

Model 2: adjusted for age and domestic role factors. Domestic role factors were changes in marital status and changes in children under $15 \mathrm{yr}$ of age from phase 2 to phase 3 .

Model 3: adjusted for age, domestic role factors, and work characteristics. Work characteristics were job category in phase 2 and changes of psychosocial work characteristics, long working hours, and shift work from phase 2 to phase 3 .

Model 4: adjusted for age, domestic role factors, work characteristics, and corresponding health variable at baseline (i.e. low mental health, poor job satisfaction, low physical health, and poor self-rated health).

\section{Discussion}

This study revealed association of sustained high WFC and deterioration of WFC with mental health and poor job satisfaction for both men and women. In men, sustained high WFC was more associated with mental health than deterioration of WFC. On the other hand, women had strong relationship between deterioration of WFC and physical health.

Previous studies have suggested a relationship between mental fatigue and burnout and $\mathrm{WFC}^{6,29)}$, and similar results were obtained from the results of this study. Furthermore, this study was a longitudinal study, and it became clear that deterioration of WFC and sustained high
WFC are predictors of poor mental health and poor job satisfaction. These trends were recognized for both men and women, whereas in men the persistence of high WFC was more strongly related to poor mental health than WFC deterioration, whereas women were more associated with WFC deterioration.

Regarding gender related to WFC and mental health, the results of previous studies are not consistent. In one study, it was a result that women's mental health and fatigue were more strongly related to WFC than $\mathrm{men}^{30)}$, and another one suggested that both men and women had a similar influence on mental health ${ }^{31)}$. A longitudinal study suggested that high WFC is a predictor of mental health deterioration in both men and women ${ }^{9}$. There was also 
research that worsening of WFC precedes deterioration of mental health in both males and females ${ }^{32)}$, and the result of this study was consistent with them.

Several cross-sectional studies have pointed out the relationship between self-related health and $\mathrm{WFC}^{29,33,34)}$. In Sweden's longitudinal study, only females recognized high WFC and self-rated health relatedness. Similarly in this study, although significant differences disappeared after adjustment for men, women's deterioration of WFC was associated with poor self-rated health.

In this study, as well as self-rated health, gender differences was recognized even in physical health outcome. After adjustment of family and work factors, relationships disappeared for men, but in women there was a relationship between WFC deterioration and poor physical health even after adjustment. Previous studies have shown that women report more frequent physical symptoms than $m^{35)}$. These include essential differences in physical and visceral perception, differences in labeling and reporting of symptoms, and differences in socialization process that recognize and disclose discomfort. Gender difference of such physical symptoms may be related to gender difference in this study. Although odds ratios did not change almost even when adjustment of family factor, adjustment of work factor showed a decrease in odds ratio for both males and females. It is suggested that work factors are more involved in the influence of WFC on health.

The present study examined the effects of five-year changes in WFC, and also clarified that the improvement of the level of conflict could have the protective effects. In men the group of improving WFC (high-low) shows a tendency toward reduced risk of mental health $(\mathrm{OR}=0.88)$ and physical health $(\mathrm{OR}=0.72)$. But kept the high tendency of reporting poor job satisfaction $(\mathrm{OR}=1.28)$. On the other hand, in women the group of improving WFC (high-low) shows a tendency toward reduced risk of poor job satisfaction $(\mathrm{OR}=0.61)$ but protective effects on mental health and physical health were observed (low mental health; $\mathrm{OR}=1.15$, low physical health; $\mathrm{OR}=2.46$ ). This might mean that mean period of change from high to low levels of WFC was not enough to alleviate the baseline effect of high WFC as regard to mental and physical health of women despite the improvement of the job satisfaction level. On the other hand, the period was enough for men who have some improvement of the WFC to alleviate the high risk for poor mental and physical health despite their sustained self-report of poor job satisfaction.

In addition, work to family and family to work conflict were analyzed respectively without adding WFC (Supple- mentary Tables 1,2$)$. Previous studies have shown some mental health disorders are associated with work to family conflict $^{36)}$. This study also found a stronger relationship between mental health and work to family conflict than family to work conflict. Further the deterioration of family to work conflict was associated with poor physical health only in women $(\mathrm{OR}=2.06)$.

Japan has strong family principles regarding the gender division of household labor and the family supports as a national policy has not much advanced yet. From this point of view, Japan has a conservative welfare regime according to Esping-Andersen's welfare state regime classification $^{37)}$. In such a regime, women are responsible for most domestic roles, such as housework and childcare. Conversely, men assume the main work role to discharge their family care and responsibilities. Despite women's social advancement in recent years and the increasing number of double-income households in Japan, women have still not achieved a similar career process to men in the workplace, although recently the movement finally has started to move toward recommending a variety of work styles irrespective of gender. The remaining traditional gender attitudes in the workplace and at home and the delay in improving the work environment are thought to have affected the gender difference in the present study.

Several limitations of this study have to be considered. First, because the participants were working civil servants, it may be difficult to generalize the results to the whole population. However, the working environment in the civil servants were regulated strictly by law, so the associations of WFC and poor health may be worse among those in private sectors. Second, there was the potential for selection bias in this study. If having a similar WFC or health problem, there is a possibility that women will be more likely to burn out than men and they may have dropped out of the survey. However, the pattern of gender difference in this research has no influence, it may rather be underestimated. Third, the findings of this study were based on 2003 and 2008 data. In Japan long working hours and poor participation of child care in men has been still pointed out, and the stress experienced by adults over $20 \mathrm{yr}$ is increasing from 2003 to $2016^{38,39)}$. The associations of WFC and poor health in this study may be underestimated. Fourth, our data did not include income and sleep data. Previous studies have shown an association between low income and sleep disorders and $\mathrm{WFC}^{15,40)}$. With these data, we may be able to refer to the social background of the gender differences in the long-term health effects of WFC. It is desirable to clarify the longterm health effects of WFC including these items. 


\section{Conclusion}

This study revealed the negative health effects of sustained high WFC and deterioration of WFC by longitudinal research. Sustained high WFC and deterioration of WFC was associated with poor mental health and poor job satisfaction for both men and women. In men, sustained high WFC was more associated with mental health than WFC deterioration. On the other hand, women had strong relationship between WFC deterioration and physical health. WFC was considered to be important factor as a social determinant of health.

\section{Conflict of Interest}

None declared.

\section{Acknowledgements}

We thank all civil servants in the local government who participated in this study. This study was supported by grants from the Ministry of Health, Labour and Welfare; the Japanese Society for the Promotion of Science; the Occupational Health Promotion Foundation, the Univers Foundation (98.04.017); the Daiwa Anglo-Japanese Foundation (03/2059), and the Great Britain Sakawa Foundation (2551). MS is supported by a British Heart Foundation Travelling Fellowship (FS/04/051).

\section{References}

1) Ministry of Health, Labour and Welfare (Japan) (2014) White Paper on the Labour and Economy 2014 Summary. Ministry of Health, Labour and Welfare.

2) Gender Equality Bureau Cabinet Office (Japan) (2014) White paper on gender equality: Cabinet Office.

3) Ministry of Internal Affairs and Communications (Japan) (2014) Labour Force Survey. Ministry of Internal Affairs and Communications.

4) Koura U, Sekine M, Yamada M, Tatsuse T (2017) Work, family, and personal characteristics explain occupational and gender differences in work-family conflict among Japanese civil servants. Public Health 153, 78-90. [Medline] [CrossRef]

5) Greenhaus JH, Beutell NJ (1985) Sources of conflict between work and family roles. Acad Manage Rev 10, 76-88. [CrossRef]

6) Demerouti E, Peeters MC, van der Heijden BI (2012) Workfamily interface from a life and career stage perspective: the role of demands and resources. Int J Psychol 47, 241-58. [Medline] [CrossRef]
7) Eby LT, Casper WJ, Lockwood A, Bordeaux C, Brinley A (2005) Work and family research in IO/OB: content analysis and review of the literature (1980-2002). J Vocat Behav 66, 124-97. [CrossRef]

8) Rantanen J, Kinnunen U, Feldt T, Pulkkinen L (2008) Work-family conflict and psychological well-being: stability and cross-lagged relations within one-and six-year follow-ups. J Vocat Behav 73, 37-51. [CrossRef]

9) Leineweber C, Baltzer M, Magnusson Hanson LL, Westerlund H (2013) Work-family conflict and health in Swedish working women and men: a 2-year prospective analysis (the SLOSH study). Eur J Public Health 23, 710-6. [Medline] [CrossRef]

10) Lidwall U, Marklund S, Voss M (2010) Work-family interference and long-term sickness absence: a longitudinal cohort study. Eur J Public Health 20, 676-81. [Medline] [CrossRef]

11) Casper WJ, Eby LT, Bordeaux C, Lockwood A, Lambert D (2007) A review of research methods in IO/OB work-family research. J Appl Psychol 92, 28-43. [Medline] [CrossRef]

12) Byron K (2005) A meta-analytic review of work-family conflict and its antecedents. J Vocat Behav 67, 169-98. [CrossRef]

13) Michel JS, Kotrba LM, Mitchelson JK, Clark MA, Baltes B (2011) Antecedents of work-family conflict: a meta-analytic review. J Organ Behav 32, 689-725. [CrossRef]

14) Hämmig $O$, Bauer G (2009) Work-life imbalance and mental health among male and female employees in Switzerland. Int J Public Health 54, 88-95. [Medline] [CrossRef]

15) Kobayashi T, Honjo K, Eshak ES, Iso H, Sawada N Tsugane S, Japan Public Health Center-based Prospective Study for the Next Generation (JPHC-NEXT) Study Group (2017) Work-family conflict and self-rated health among Japanese workers: How household income modifies associations. PLoS One 12, e0169903. [Medline] [CrossRef]

16) Sekine M, Tatsuse T, Cable N, Chandola $T$, Marmot $M$ (2014) Socioeconomic and gender inequalities in job dissatisfaction among Japanese civil servants: the roles of work, family and personality characteristics. Ind Health $\mathbf{5 2}$, 498-511. [Medline] [CrossRef]

17) Chandola $T$, Martikainen $P$, Bartley $M$, Lahelma E, Marmot M, Michikazu S, Nasermoaddeli A, Kagamimori S (2004) Does conflict between home and work explain the effect of multiple roles on mental health? A comparative study of Finland, Japan, and the UK. Int J Epidemiol 33, 884-93. [Medline] [CrossRef]

18) Lallukka $T$, Lahelma $E$, Rahkonen $O$, Roos E, Laaksonen E, Martikainen P, Head J, Brunner E, Mosdol A, Marmot M, Sekine M, Nasermoaddeli A, Kagamimori S (2008) Associations of job strain and working overtime with adverse health behaviors and obesity: evidence from the Whitehall II Study, Helsinki Health Study, and the Japanese Civil Servants Study. Soc Sci Med 66, 1681-98. [Medline] [CrossRef] 
19) Grzywacz JG, Marks NF (2000) Reconceptualizing the work-family interface: an ecological perspective on the correlates of positive and negative spillover between work and family. J Occup Health Psychol 5, 111-26. [Medline] [CrossRef]

20) Lallukka T, Chandola T, Roos E, Cable N, Sekine M, Kagamimori S, Tatsuse T, Marmot M, Lahelma E (2010) Work-family conflicts and health behaviors among British, Finnish, and Japanese employees. Int J Behav Med 17, 134-42. [Medline] [CrossRef]

21) Fukuhara S, Suzukamo Y, Bito S, Kurokawa K (2001) Manual of SF-36 Japanese version 1.2. Public Health Research Foundation, Tokyo (in Japanese).

22) Lins L, Carvalho FM (2016) SF-36 total score as a single measure of health-related quality of life: Scoping review. SAGE Open Med 4, 2050312116671725 . [Medline] [CrossRef]

23) Bailis DS, Segall A, Chipperfield JG (2003) Two views of self-rated general health status. Soc Sci Med 56, 203-17. [Medline] [CrossRef]

24) Faragher EB, Cass M, Cooper CL (2005) The relationship between job satisfaction and health: a meta-analysis. Occup Environ Med 62, 105-12. [Medline] [CrossRef]

25) Tatsuse T, Sekine M (2011) Explaining global job satisfaction by facets of job satisfaction: the Japanese civil servants study. Environ Health Prev Med 16, 133-7. [Medline] [CrossRef]

26) Wanous JP, Reichers AE, Hudy MJ (1997) Overall job satisfaction: how good are single-item measures? J Appl Psychol 82, 247-52. [Medline] [CrossRef]

27) Kawada T, Suzuki S (2008) Physical symptoms and psychological health status by the type of job. Work 31, 397-403. [Medline]

28) Alves MG, Hökerberg YH, Faerstein E (2013) [Trends and diversity in the empirical use of Karasek's demandcontrol model (job strain): a systematic review]. Rev Bras Epidemiol 16, 125-36 (in Portuguese). [Medline] [CrossRef]

29) Eshak ES, Kamal NN, Seedhom AE, Kamal NN (2018) Work-family conflict and self-rated health among dwellers in Minia, Egypt: financial strain vs social support. Public Health 157, 69-76. [Medline] [CrossRef]

30) Canivet C, Ostergren PO, Lindeberg SI, Choi B, Karasek
R, Moghaddassi M, Isacsson SO (2010) Conflict between the work and family domains and exhaustion among vocationally active men and women. Soc Sci Med 70, 1237-45. [Medline] [CrossRef]

31) Frone MR (2000) Work-family conflict and employee psychiatric disorders: the National Comorbidity Survey. J Appl Psychol 85, 888-95. [Medline] [CrossRef]

32) Nilsen W, Skipstein A, Demerouti E (2016) Adverse trajectories of mental health problems predict subsequent burnout and work-family conflict - a longitudinal study of employed women with children followed over 18 years. BMC Psychiatry 16, 384. [Medline] [CrossRef]

33) Winter T, Roos E, Rahkonen O, Martikainen P, Lahelma E (2006) Work-family conflicts and self-rated health among middle-aged municipal employees in Finland. Int Behav Med 13, 276-85. [CrossRef]

34) Griep RH, Toivanen S, van Diepen C, Guimarães JMN, Camelo LV, Juvanhol LL, Aquino EM, Chor D, Baseline Data from the Brazilian Longitudinal Study of Adult Health (ELSA-Brasil) (2016) Work-family conflict and self-rated health: the role of gender and educational level. Baseline data from the Brazilian Longitudinal Study of Adult Health (ELSA-Brazil). Int J Behav Med 23, 372-82. [Medline] [CrossRef]

35) Barsky AJ, Peekna HM, Borus JF (2001) Somatic symptom reporting in women and men. J Gen Intern Med 16, 266-75. [Medline] [CrossRef]

36) Eshak ES (2019) Mental health disorders and their relationship with work-family conflict in Upper Egypt. J Fam Econ Issues 40, 623-32. [CrossRef]

37) Esping-Andersen G (1990) Three worlds of welfare capitalism. Oxford Press, Oxford.

38) Ministry of Internal Affairs and Communications (2011) Survey on time use and leisure activities. Ministry of Internal Affairs and Communications.

39) Ministry of Health, Labour and Welfare (2003-2016) Comprehensive Survey of Living Conditions. Ministry of Health, Labour and Welfare.

40) Eshak ES (2019) Work-to-family conflict rather than family-to-work conflict is more strongly associated with sleep disorders in Upper Egypt. Ind Health 57, 351-8. [Medline] 